\title{
Integrin subunits alpha5 and alpha6 regulate cell cycle by modulating the chk1 and Rb/E2F pathways to affect breast cancer metastasis
}

\author{
Yanfang Wang ${ }^{1 \dagger}$, Sylvia Shenouda ${ }^{1 \dagger}$, Somesh Baranwal ${ }^{1 \dagger}$, Rajamani Rathinam, Prachi Jain ${ }^{1}$, Lili Bao²,
} Siddhartha Hazari ${ }^{2}$, Srikanta Dash² and Suresh K Alahari ${ }^{1 *}$

\begin{abstract}
Background: Although integrins have been implicated in the progression of breast cancer, the exact mechanism whereby they exert this regulation is clearly not understood. To understand the role of integrins in breast cancer, we examined the expression levels of several integrins in mouse breast cancer cell lines by flow cytometry and the data were validated by Western and RT-PCR analysis. The importance of integrins in cell migration and cell invasion was examined by in vitro assays. Further the effect of integrins on metastasis was investigated by in vivo experimental metastasis assays using mouse models.
\end{abstract}

Results: Integrin $\alpha 5$ subunit is highly expressed in the nonmetastatic cell line 67NR and is significantly low in the highly invasive cell line 4T1. In contrast, expression levels of integrin $\alpha 6$ subunit are high in 4T1 cells and low in 67NR cells. In vitro data indicated that overexpression of $\alpha 5$ subunit and knockdown of $\alpha 6$ integrin subunit inhibited cell proliferation, migration, and invasion. Our in vivo findings indicated that overexpression of integrin $\alpha 5$ subunit and knockdown of $\alpha 6$ subunit decreased the pulmonary metastasis property of 4T1 cells. Our data also indicated that overexpression of alpha 5 integrin subunit and suppression of alpha6 integrin subunit inhibited cells entering into $S$ phase by up-regulating p27, which results in downregulation of cyclinE/CDK2 complexes, This suggests that these integrins regulate cell growth through their effects on cell-cycle-regulated proteins. We also found that modulation of these integrins upregulates E2F, which may induce the expression of chk1 to regulate cdc25A/cyclin E/CDK2/Rb in a feedback loop mechanism.

Conclusion: This study indicates that Integrin $\alpha 5$ subunit functions as a potential metastasis suppressor, while $\alpha 6$ subunit functions as a metastasis promoter. The modulation of integrins reduces cdc $25 \mathrm{~A}$, another possible mechanism for downregulation of CDK2. Taken together we demonstrate a link between integrins and the chk1cdc25-cyclin E/CDK2-Rb pathway.

\section{Background}

Tumor metastasis is a highly complex multistep process involving unregulated cell growth, cell-cell and cellmatrix interactions, cell adhesion, angiogenesis, and growth of new cancer colonies [1]. During these steps, the expression level of some genes is altered. Thus, these genes, once identified, can serve as bio-markers of metastatic diagnosis and prognosis. Over the past

\footnotetext{
* Correspondence: salaha@|suhsc.edu

† Contributed equally

'Department of Biochemistry and Molecular Biology, Stanley Scott Cancer

Center, LSU Health Sciences Center, New Orleans, LA 70112, USA

Full list of author information is available at the end of the article
}

decade, a variety of genes have been identified that are altered in tumor growth and metastasis [2].

Integrins are a family of transmembrane glycoprotein adhesion receptors that mediate cell-matrix and cell-cell adhesion. They are the main receptors for sensing the extracellular environment of the cell [3]. Integrins form heterodimers of $\alpha$ and $\beta$ subunits [4]. Eighteen $\alpha$ subunits and eight $\beta$ subunits can associate to form 24 unique integrin heterodimers. Numerous studies have shown that in addition to sensing the extracellular environment, integrins are involved in various intracellular pathways, including cell adhesion, migration, polarity, survival, growth and death $[3,5,6]$, suggesting their

\section{() Biomed Central}

(c) 2011 Wang et al; licensee BioMed Central Ltd. This is an Open Access article distributed under the terms of the Creative Commons Attribution License (http://creativecommons.org/licenses/by/2.0), which permits unrestricted use, distribution, and reproduction in any medium, provided the original work is properly cited. 
important role in cancer [4]. Furthermore, integrins were shown to be differentially expressed during tumor growth and progression, making them potential targets for cancer diagnosis and therapy $[3,5,6]$.

The mechanisms whereby integrins function in tumor cells are yet to be determined. However, some cancerrelated proteins, such as focal adhesion kinase (FAK) [7] and Nischarin [8] can bind to and interact with integrins. Therefore, we investigated whether integrins are differentially expressed in highly metastatic cells compared with non-metastatic cells, and examined the effect of these differentially expressed integrins on cell proliferation, invasion and the potential of metastasis.

In this study we used mouse breast cancer cell lines $4 \mathrm{~T} 1,4 \mathrm{~T} 07$, and $67 \mathrm{NR}$ because they represent a good model for the study of breast cancer metastasis. $4 \mathrm{~T} 1$, $4 \mathrm{~T} 07$, and $67 \mathrm{NR}$ are derived from the same BALB/c mammary tumor and are highly tumorigenic, but vary in their metastatic potential. 4T1 widely disseminates, resulting in secondary tumors in the lung, liver, bone, and brain; 4T07 spreads to the lung and liver but cannot establish metastatic nodules; 67NR does not metastasize $[9,10]$. Our study shows that integrin $\alpha 5$ subunit functions as a candidate metastasis suppressor, while $\alpha 6$ subunit promotes tumor metastasis in $4 \mathrm{~T} 1$ cell lines through the modulation of pathways regulated by the cell cycle.

\section{Materials and methods Cell lines}

Mouse mammary carcinoma cells 4T1, 4T07, and 67NR were cultured in Dulbecco's Modified Eagle's Medium (DMEM) supplemented with 10\% fetal bovine serum (FBS). Cells were incubated at $37^{\circ} \mathrm{C}$ with $5 \%(w / v) \mathrm{CO}_{2}$ and $95 \%(\mathrm{w} / \mathrm{v})$ air mixture.

\section{Flow cytometry}

One million 4T1, 4T07, and 67NR cells were incubated with primary antibodies against integrins $\alpha 4$ (clone PS/ 2), $\alpha 5$ (clone 5H10-27), $\alpha 6$ (clone NKI-GoH3), $\beta 1$ (clone MB1.2), $\beta 2$ (clone M18/2), $\alpha 2 \beta 1$ (clone BMA2.1), $\alpha 5 \beta 1$ (clone BMA5), and $\alpha v \beta 6$ (clone 10D5) for $30 \mathrm{~min}$ at $4^{\circ} \mathrm{C}$ in phosphate-buffered saline containing $1 \%$ FBS. Cells were then washed twice with ice-cold PBS and incubated with FITC-conjugated secondary antibodies $(1: 1,250)$ for $30 \mathrm{~min}$ at $4^{\circ} \mathrm{C}$. Most antibodies were purchased from Millipore (Madison, WI); the exception was integrin $\alpha 5$, which was purchased from Abcam (Cambridge, MA). Relative amounts of cell surface integrins were determined using a FACScan cytometer with CellQuest software (Becton-Dickinson, San Jose, CA).

\section{RT-PCR}

Total RNAs from these cell lines were isolated using a RNeasy kit (Qiagen, Valencia, CA). RNA quality was determined with the Agilent Bioanalyser 2100 and RNA Nano 6000 Labchip kit (Agilent Technologies, Palo Alto, CA). RNA concentrations were determined with a NanoDrop apparatus (NanoDrop Technologies). RT-PCR was done to confirm expression of integrins $\alpha 5$ and $\alpha 6$ by one-step RT-PCR (Qiagen). Briefly, the $25 \mu \mathrm{l}$ RT-PCR reaction included $100 \mathrm{ng}$ total RNA, $5 \mu \mathrm{l} 5 \times \mathrm{RT}$-PCR buffer, $0.4 \mathrm{mM}$ dNTP, $0.6 \mu \mathrm{M}$ forward and reverse primers, and $1 \mu \mathrm{l}$ enzyme mix. The reactions were incubated in a 96-well plate at $50^{\circ} \mathrm{C}$ for $30 \mathrm{~min}$ and $95^{\circ} \mathrm{C}$ for $15 \mathrm{~min}$, followed by 25 cycles of $95^{\circ} \mathrm{C}$ for $15 \mathrm{sec}, 60^{\circ} \mathrm{C}$ for $30 \mathrm{sec}, 72^{\circ} \mathrm{C}$ for $30 \mathrm{~s}$, and $72^{\circ} \mathrm{C}$ for $7 \mathrm{~min}$. The primers used in RTPCR were:

For integrin $\alpha$ 5: forward: 5'-GGACCAAGACGGCTACAATGATGT-3';

Reverse: 5'-ACCTGGGAAGGTTTAGTGCTCAGT-3'.

For Integrin $\alpha 6$ : forward: 5'-AAAGAGACATGAAGTCCGCGCATC-3';

Reverse: 5'-AACAATGTCTTGCCACCCATCTGC-3'.

For CHK1: forward: 5'-TGGACAAACTGGTTCAGGGCAT-3';

Reverse: 5'-TGCTCACAACATCGCTGAGCTT-3'.

For E2F1: forward: 5'-ACCCAGGGAAAGGTGTGAAA-3';

Reverse: 5'-AAAGCAGTTGCAGCTGTGTGGT-3'. For GAPDH forward: 5'-AACATCATCCCTGCATCCACTGGT-3';

Reverse: 5'-TGTTGAAGTCGCAGGAGACAACCT-3'.

The RT-PCR products were determined by electrophoresis on $2 \%$ agarose gel stained with ethidium bromide.

\section{Western blotting}

Cells were washed twice using ice cold PBS. Cell lysates were prepared using RIPA buffer (50 mM Tris, $\mathrm{pH}$ 7.5; 1\% NP-40; $0.1 \%$ sodium deoxycholate; $150 \mathrm{mM} \mathrm{NaCl}$; $50 \mathrm{mM} \mathrm{NaF}$; and $1 \mathrm{mM}$ sodium pyrophosphate). Lysates were centrifuged at $20,000 \times g$ for $20 \mathrm{~min}$ at $4^{\circ} \mathrm{C}$. Small aliquots $(10 \mu \mathrm{l})$ of the supernatant were used for determining protein concentrations by a bicinchonic acid assay (Pierce; Rockford, IL). Proteins (20-50 $\mu \mathrm{g}$ ) were separated by SDS-polyacrylamide electrophoresis on $6 \%$ or $12 \%$ polyacrylamide gels and transferred to PVDF membranes (GE Healthcare Biosciences, Piscataway, NJ). Blots were blocked in 5\% milk and 0.1\% Tris-buffered saline-Tween 20 for $1 \mathrm{hr}$ at room temperature. Blots were incubated with antibodies against integrin $\alpha 5$ subunit (1:1000; Millipore, Madison, WI) and integrin $\alpha 6$ subunit (1:500; Santa Cruz Biotechnology, Santa Cruz, CA). Membranes were washed $4 \mathrm{X}$ for 5 min each time using PBS Tween 20 and incubated with anti-mouse or anti-rabbit horseradish-peroxidase-conjugated secondary antibodies (1:2,000; Santa Cruz Biotechnology). 
Detection of the signal was done using an ECL immunoblotting detection system (GE Healthcare Biosciences).

\section{Construction of stable cell lines overexpressing integrin $\alpha 5$ and knockdown integrin $\alpha 6$}

We used the expression plasmid pcDNA 3.1/ITGA5, which contains the full length of integrin $\alpha 5$ subunit, to transfect 4T1 cells by the Lipofectamine 2000 method (Life Technologies, Rockville, MD). The transfected cells were subjected to $1 \mathrm{mg} / \mathrm{mL}$ G418 selection. Several G418-resistant clones were tested for integrin $\alpha 5$ subunit overexpression. The mixture of positive clones was used for further studies.

Two integrin $\alpha 6$ subunit oligos were designed by selecting appropriate sequences from the mouse integrin $\alpha 6$ gene (NM_008397) and named shRNA-1 and shRNA-control. The sequences of the two shRNAs were as follows:

shRNA-: 5'-GATCCCCCCTTGTACACGGATTGAA TTTCAAGAGAATT CAATCCGTGTACAAGGTT TTTA-3';

shRNA-control: 5'-GATCCCCGGACAACGTGAT CCGGAA ATTCAAGAGATTTCCGGATCACGTTGT CCTTTTTA-3'

The double strands for shRNA-1 and shRNA-control oligos were cloned into GeneScript shRNA expression vector, pRNAT-H1.1/Neo (Cat\# SD1213-Genescript, $\mathrm{NJ}$ ), using the BamH1 and HindIII restriction enzyme sites. The oligo insertion was confirmed by sequencing. After plasmid transfection, cells were cultured in G-418 $(500 \mathrm{ug} / \mathrm{ml})$ and several clones were isolated. The individual clones were characterized and positive clones were selected RT-PCR and Western blot analysis.

\section{Cell proliferation analysis}

To examine cell proliferation, we used MTT calorimetry assays (Millipore, Madison, WI). Cells were harvested, resuspended, and plated in 96 -well plates at $1 \times 10^{3}$ cells per well in $100 \mu \mathrm{L}$ of cell culture medium and maintained at $37^{\circ} \mathrm{C}$ in a humidified incubator containing $5 \% \mathrm{CO} 2$. After every $24 \mathrm{~h}, 10 \mu \mathrm{L}$ of the MTT solution was added to the triplicate wells and incubated at $37^{\circ} \mathrm{C}$ for another $4 \mathrm{~h}$. Also, $100 \mu \mathrm{L}$ of color development solution was added and incubated for $10 \mathrm{~min}$ to dissolve the crystal completely. Then we measured the absorbance at $572 \mathrm{~nm}$, using a plate reader to calculate the numbers of vital cells in each well.

\section{Cell migration and cell invasion analysis}

In vitro cell migration and invasion assays were done as per our previously reported protocols $[8,11]$. Briefly, 4T1 (control), 4T1-GFP, 4T1- $\alpha 5$, or 4T1- $\alpha 6$. shRNA1 cells $\left(1 \times 10^{5}\right)$ were suspended in $100 \mu \mathrm{L}$ of serum-free
DMEM and added on top of the transwell $(8.0 \mu \mathrm{M}$ pore size; Corning, NY) chambers (for migration) or on top of the Matrigel-coated transwells $(30 \mu \mathrm{L}$ of serum-free DMEM-diluted matrigel; BD Biosciences, San Jose, CA) (for invasion) in triplicate. The DMEM plus $10 \%$ FBS culture medium was added to the lower chamber to serve as a chemoattractant. After $6 \mathrm{~h}$ (migration) or $24 \mathrm{~h}$ (invasion) of incubation at $37^{\circ} \mathrm{C}$, the upper surfaces of the filters were carefully wiped with a cotton-tipped applicator. The filters were fixed with $4 \%$ paraformaldehyde in PBS and stained with $0.1 \%$ crystal violet solution. In some cases, cell migration was performed either on fibronectin or laminin matrices. Cells that had migrated or invaded (Matrigel) through the transwell filter pores toward the lower surface of the filters were counted in five different fields under a light microscope.

\section{Cell cycle analysis}

4T1 (control), 4T1-GFP, 4T1- $\alpha 5$, and 4T1- $\alpha 6$-shRNA1 cells were stained for DNA content as per our previously described protocols [12]. Briefly, cells were trypsinized and resuspended in $200 \mu \mathrm{L}$ ice-cold PBS, after which $4 \mathrm{ml}$ of cold $70 \%$ ethanol was added to the mixture. Cells were incubated at $4^{\circ} \mathrm{C}$ for $45 \mathrm{~min}$. Subsequently, cells were centrifuged at $1,500 \mathrm{~g}$ for $10 \mathrm{~min}$ at $4^{\circ} \mathrm{C}$ and resuspended in PI master mix, consisting of propidium iodide $40 \mathrm{ug} / \mathrm{ml}$ and RNAse $100 \mathrm{ug} / \mathrm{ml}$ (Sigma) at $37^{\circ} \mathrm{C}$ for $30 \mathrm{~min}$. Cells were then analyzed using an LSR II cytometer. PI staining intensity was determined by Modfit software.

\section{Cell-cycle genes PCR Array}

Total RNA was extracted and measured as previously described [12]. RNA was used to probe GE arrays containing cell-cycle-related genes as per the manufacturer's recommendations (SuperArray Bioscience). Raw data were normalized by GEarray Analyzer software. Data were normalized with control groups (4T1- $\alpha 5$ data normalized with 4T1-GFP and 4T1 $\alpha 6-1$ data normalized with $4 \mathrm{~T} 1$ control shRNA).

\section{In-vivo metastasis assay}

Twenty five nude mice (NCI) were maintained as per the guidelines of the AALAC and the IACUC LSU Health Sciences Center at New Orleans. These mice were randomly allocated to five groups for tail vein injections of 4T1 control, 4T1-GFP, 4T1- $\alpha 5$, or 4T1$\alpha 6$-shRNA1 cells. Cells were grown to $80 \%$ confluency and harvested in cold PBS. $1 \times 10^{6}$ cells in 0.1 ml PBS were injected into nude mice via lateral tail vein injection. These mice were then used in the following experiments, each of which was repeated three times. 


\section{Immunohistochemistry}

After 4 weeks, mice were euthanized. Their lungs were removed and perfused with buffered formalin through the cannulated trachea. Paraffin wax sections were stained with hematoxylin and eosin (H\&E) and Ki67 using standard procedures, and the sections were examined by light microscopy.

\section{India ink lung staining}

At 4 weeks after tail vein injection, mice were sacrificed and India ink (15\%) was injected into their lungs through the trachea. The lungs were fixed in Fekete's solution $(100 \mathrm{~mL}$ of $70 \%$ alcohol, $10 \mathrm{~mL}$ formalin, and 5 $\mathrm{mL}$ glacial acetic acid) at room temperature. After destaining, the lungs were photographed.

\section{Statistical analysis}

Every experiment was repeated at least three times and statistical analysis was performed by one way ANOVA using JMP5.0 Software (SAS Inc, Cary, NC). Fisher's LSD post-hoc test was applied to assess differences of expression levels between each cell type. A value of $\mathrm{p} \leq$ 0.05 was considered statistically significant.

\section{Results}

\section{In $4 \mathrm{~T} 1$ cells integrin $\alpha 5$ subunit levels are low and} integrin $\alpha 6$ subunit levels are high

Since integrins are thought to have a major role in regulating tumor growth and metastasis, we examined the expression levels of integrins in highly invasive (4T1 and
4T07) and noninvasive (67NR) mouse breast cancer cells. Using FACS analysis, we measured the expression levels of 7 integrins, $\alpha 4, \alpha 5, \alpha 6, \beta 1, \beta 2, \alpha 2 \beta 1$, and $\alpha v \beta 6$. Our results showed that integrin $\alpha 5$ subunit levels were lowest in 4T1, moderate in 4T07, and highest in 67NR cells (Figure 1A). In contrast, integrin $\alpha 6$ subunit expression was highest in 4T1, moderate in 4T07, and lowest in 67NR cells (Additional File 1, Figure 1B). Expression of the other integrins $(\alpha 4, \beta 1, \beta 2, \alpha 2 \beta 1$, $\alpha v \beta 6)$ was very low in these cell lines (Additional File $1)$. RT-PCR and Western blot analysis validated the different levels of expression of integrin subunits $\alpha 5$ and $\alpha 6$ in $4 \mathrm{~T} 1,4 \mathrm{~T} 07$, and 67NR cells (Figure 2A, B). These findings suggest that the $\alpha 5$ and $\alpha 6$ integrins may have a critical role in tumor growth and metastasis.

To investigate the potential role of integrin subunits $\alpha 5$ and $\alpha 6$ on tumor cell invasion and metastasis of 4T1 cells, we stably transfected these cells with full-length cDNA for mouse integrin $\alpha 5$ subunit and pRNAT-H1.1/ neo, which contained the shRNA-control or shRNA-1 for mouse integrin $\alpha 6$ subunit. 4T1-GFP was also used as a control. Mixtures of G418 resistant clones from these stable transfections were tested for the integration of integrin $\alpha 5$ subunit overexpression and integrin $\alpha 6$ subunit knockdown by RT-PCR and Western blot analyses. Our findings demonstrate that the expression levels of integrin $\alpha 5$ in the transfected cells increased as compared with levels in controls (Figure 2C). For integrin $\alpha 6$ subunit knockdown stable cells, both RT-PCR and Western blot analyses demonstrated that shRNA-1

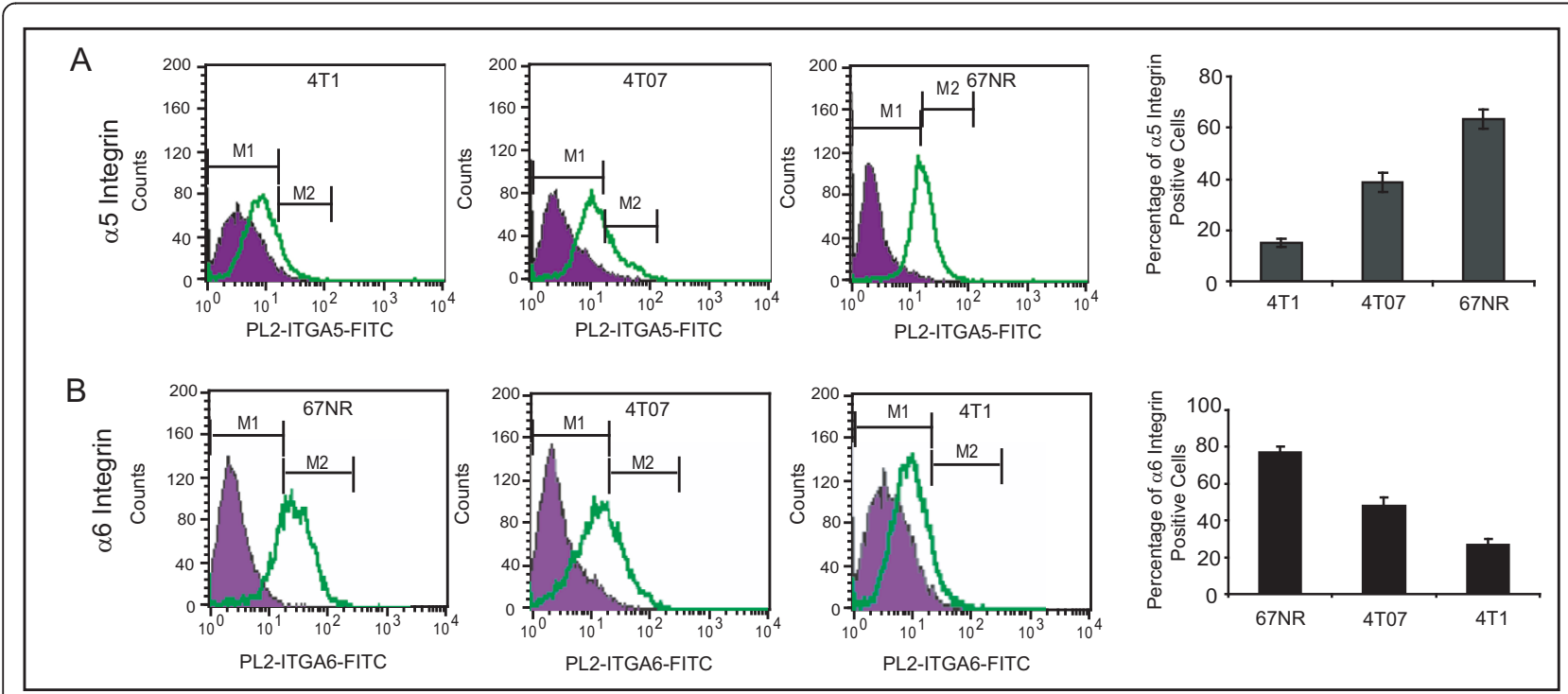

Figure 1 Flow cytometric analysis of integrins. Analysis was performed for integrin $\alpha 5$ (A) and $\alpha 6$ (B) on mouse breast cancer cell lines 4 T1 (control), as well as 4T07 and 67NR. The fluorescence signals of unstained cells (primary antibody omitted) for each cell type were presented as blue peaks and served as the basal level of cell-surface expression. The fluorescence signal for integrin $\alpha 5$ and $\alpha 6$ subunits were presented as open peaks. Histograms presented the positive cell percentage of each cell type and the differences are statistically significant ( $\mathrm{P}<0.01)$. All experiments were repeated three times. 


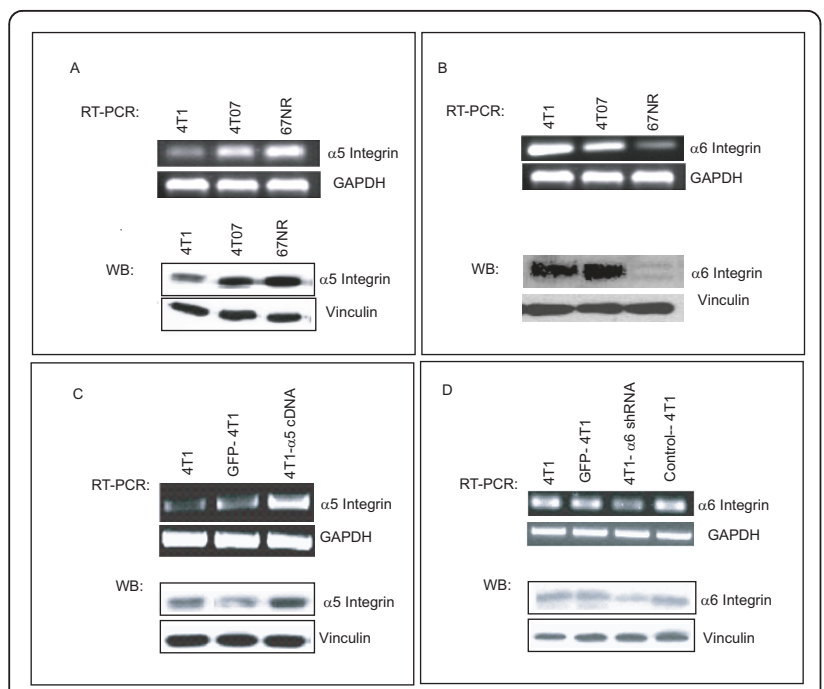

Figure 2 Validation of expression of integrins by RT-PCR and Western blot analysis. Expression levels of integrin $\alpha 5(\mathbf{A})$ and $\alpha 6$ subunits (B) were validated by RT-PCR and Western blotting. RT-PCR was done using the integrin $\alpha 5$ - and $\alpha 6$-specific primers. GAPDH was used as the loading control. Cell lysates were prepared and Western blotted with anti-integrin $\alpha 5$ or anti-integrin $\alpha 6$ antibody. Vinculin blotting was used for equal loading. Integrin $\alpha 5$ overexpression (C) and $\alpha 6$ knockdown (D) were also validated by RT-PCR and Western blot. Stable cell lines overexpressing integrin $\alpha 5$ and knockdown $\alpha 6$ were established. RNA and protein lysates were used to demonstrate the expression of the plasmids.

can efficiently target mouse integrin $\alpha 6$ mRNA. Moreover, the expression level of $\alpha 6$ was significantly decreased (Figure 2D). In contrast, shRNA-control (alpha6-2) did not affect integrin $\alpha 6$ subunit expression at either the RNA or protein level (Figure 2D).

\section{Integrin $\alpha 5$ subunit overexpression and $\alpha 6$ subunit knockdown inhibit 4T1 cell proliferation}

Since cell proliferation is an important regulator of tumor growth, we examined the potential roles of integrin $\alpha 5$ and $\alpha 6$ genes on cell growth. We used 4T1 control, GFP-4T1, 4T1- $\alpha 5$, and 4T1- $\alpha 6$-shRNA1 cells and measured cell growth by the MTT method. The proliferation curves of $4 \mathrm{~T} 1$ control and 4T1-GFP cells were quite similar at all time points (Figure $3 \mathrm{~A}$ ). The in vitro proliferation ability of $4 \mathrm{~T} 1$ cells was significantly inhibited at $48 \mathrm{hr}$ by overexpression of integrin $\alpha 5$ subunit $(0.30 \pm 0.08$ versus $0.61 \pm 0.07$ for $4 \mathrm{~T} 1-\alpha 5$ and $4 \mathrm{~T} 1-$ GFP, respectively; $\mathrm{p}<0.01)$ and $96 \mathrm{hr}(0.88 \pm 0.14$ versus $1.47 \pm 0.09$ for $4 \mathrm{~T} 1-\alpha 5$ and 4T1-GFP, respectively; $\mathrm{p}$ $<0.01)$. Similarly, integrin $\alpha 6$ subunit knockdown had a significant inhibitory effect on $4 \mathrm{~T} 1$ cell proliferation at $48 \mathrm{hr}(0.41 \pm 0.04$ versus $0.61 \pm 0.07$ for $4 \mathrm{~T} 1-\alpha 6$ shRNA1 and 4T1-GFP, respectively; $\mathrm{p}<0.01)$ and 96 hours $(1.01 \pm 0.21$ versus $1.47 \pm 0.09, \mathrm{p}<0.01)$ (Figure $3 \mathrm{~A})$. The effect of $\alpha 6$ knockdown on cell proliferation

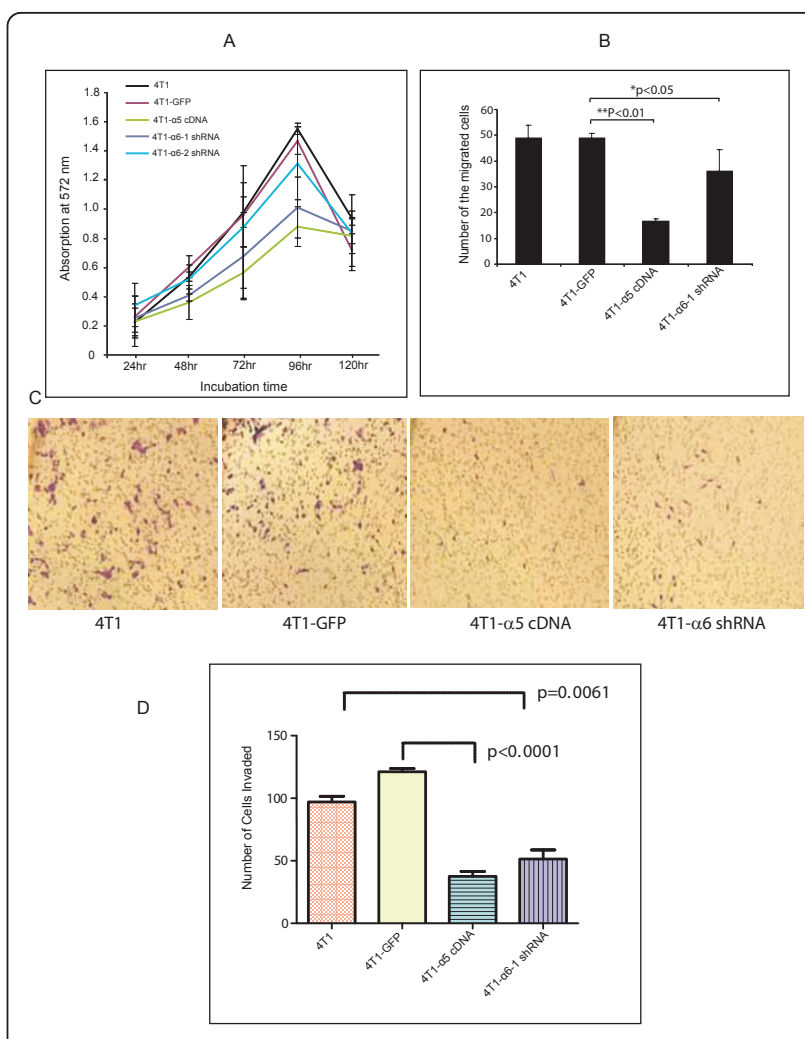

Figure 3 Modulation of integrin expression inhibits cell proliferation, migration and invasion. A. Cell proliferation of 4T1 cells. 4T1 control, 4T1-GFP, 4T1- $\alpha 5$, and 4T1- $\alpha 6$-shRNA1 cells were seeded and MTT assays done at 24-hr intervals. MTT data were plotted based on the average absorbance value and standard deviation. The $Y$ axis presents the absorbance at $572 \mathrm{~nm}$; the $X$ axis represents incubation time. Black curve: 4T1 control; red curve: 4T1GFP cells; green curve: 4T1- $\alpha 5$ cells; blue curve: 4T1- $\alpha 6$-shRNA1 cells. ** $p<0.01$ (as compared to GFP-4T1). We found that the in-vitro proliferation ability of $4 \mathrm{~T} 1$ cells is inhibited by overexpression of integrin $\alpha 5$ and knockdown of integrin $\alpha 6$. B. A transwell migration assay was done for 4T1 (control), GFP-4T1, 4T1- $\alpha 5$, and 4T1- $\alpha 6-$ shRNA1 cells. The number of cells that migrated to the lower surface of the filter membrane was counted in 5 random fields under a light microscope $(\times 200)$. The ability of 4 T1 cells to migrate was significantly diminished by overexpression of integrin $\alpha 5$ ( $p<$ 0.01 ) and knockdown of 4T1- $\alpha 6-$ shRNA1 $(p<0.05)$. C.

Representatives of cell migration figures for each cell type. D. A cell invasion assay was done for 4T1, 4T1-GFP, 4T1- $\alpha 5$, and 4T1- $\alpha 6$ shRNA1 cells. $0.1 \%$ crystal violet solution was used to stain the lower chamber of transwell. The number of cells that invaded the Matrigel and penetrated the transwell pore to the lower surface was counted in 5 random fields under a light microscope $(\times 200)$.

Overexpression of integrin $\alpha 5$ and knockdown of $\alpha 6$ inhibited the ability of $4 T 1$ cells to invade $(p<0.01)$.

was not quite as robust as that of $\alpha 5$ overexpression. However, alpha6 knockdown did significantly inhibit cell proliferation (Figure 3A). These results suggest that overexpression of $\alpha 5$ and knockdown of $\alpha 6$ reduce cell growth in vitro. 
Integrin $\alpha 5$ subunit overexpression and $\alpha 6$ subunit knockdown inhibit $4 \mathrm{~T} 1$ cell migration and cell invasion Cell migration, a central process in the development and maintenance of multicellular organisms, has been shown to be involved in tumor formation and metastasis. Therefore, using the classic transwell in vitro cell migration assays, we investigated whether integrin $\alpha 5$ subunit overexpression and integrin $\alpha 6$ subunit knockdown affect the migration ability of $4 \mathrm{~T} 1$ cells. As shown in Figure $3 \mathrm{~B}$ and $3 \mathrm{C}$, the in vitro migration ability of $4 \mathrm{~T} 1$ $\alpha 5$ cells was significantly decreased as compared to that of $4 \mathrm{~T} 1$ control and $4 \mathrm{~T} 1-\mathrm{GFP}$ cells. The numbers of migrated cells were $17.67 \pm 1.0,49 \pm 4.95$ and $49 \pm$ 1.86 , respectively, for $4 \mathrm{~T} 1-\alpha 5,4 \mathrm{~T} 1$ control, and $4 \mathrm{~T} 1-$ GFP cells $(\mathrm{p}<0.01)$. Similarly, the number of 4T1- $\alpha 6-$ shRNA1 cells $(36.17 \pm 8.25)$ that migrated through the transwell membrane was significantly lower than the number of $4 \mathrm{~T} 1$ control cells $(49 \pm 4.95)$ and $4 \mathrm{~T} 1$-GFP cells $(49 \pm 1.86)$ that did so $(\mathrm{p}<0.05)$ (Figure $3 \mathrm{~B}, \mathrm{C})$. Furthermore, to define the functional changes of the integrins, migration of $4 \mathrm{~T} 1$ and $67 \mathrm{NR}$ cells was carried out using either alpha5 integrin or alpha6 integrin functional antibodies. As shown in additional file 2, migration of 67NR cells (that have high levels of $\alpha 5$ integrin) was enhanced in the presence of $\alpha 5$ integrin blocking antibody, further suggesting $\alpha 5$ integrin suppresses cell migration. Also migration of $4 \mathrm{~T} 1$ cells (that have high levels of $\alpha 6$ integrin) was decreased in the presence of $\alpha 6$ integrin blocking antibody (Additional File 2).

Cell invasion is an important regulator of tumor growth and metastasis. To explore the functional effect of integrin $\alpha 5$ and $\alpha 6$ genes on the invasiveness of 4T1 cells, we did in vitro Matrigel invasion assays on these cell lines. Our results showed that the numbers of 4T1$\alpha 5$ and 4T1- $\alpha 6$-shRNA1 cells that passed through the Matrigel and transwell membrane were significantly lower than the number of cells in the 4T1-GFP control group that did so, indicating that these integrins have important role in cell invasion (Figure 3D).

\section{Integrin $\alpha 5$ overexpression and $\alpha 6$ knockdown inhibit metastasis}

Since $\alpha 5$ and $\alpha 6$ have dramatic effects on tumor cell migration and invasion, we hypothesized that these integrins may also have an effect on breast cancer metastasis. Thus we examined the effect of integrins on metastasis in vivo. 4T1 cells overexpressing $\alpha 5$ integrin subunit and $\alpha 6$ subunit underexpressing cells (with their controls) were injected into the tail veins of nude mice. Lung metastasis was examined four weeks later. Mice injected with 4T1- $\alpha 5$ and 4T1- $\alpha 6$-shRNA1 cells showed a dramatic decrease in pulmonary metastases, while mice injected with 4T1 control and 4T1-GFP cells produced many metastatic nodules (Figure $4 \mathrm{Ai}, \mathrm{Bi}, \mathrm{Ci}, \mathrm{Di}$ ).
When we dissected the lungs and filled them with 15\% India ink, the metastatic tumors, after fixation in Fekete's solution, appeared as white nodules on the black lung surface (Figure 4Aii, Bii, Cii, Dii). H\&E staining of the lungs of these mice showed that the presence of $\alpha 5$ and the reduction of $\alpha 6$ reduced lung metastases, while their controls had large numbers of metastases (Figure 4Aiii, Biii, Ciii, Diii). In contrast, the lungs of mice injected with vector control cells were heavily infiltrated with metastases. To our surprise $4 \mathrm{~T} 1-\alpha 5$ and 4T1- $\alpha 6$-shRNA1 cells did not have any effect on breast tumor growth, when we injected them into mammary fat pads (data not shown)., and the reasons for these results are currently unknown. These data suggest that the $\alpha 5$ integrin subunit may function as a metastasis suppressor while $\alpha 6$ subunit may function as a metastasis promoter.

Our in vitro studies suggest that integrins have an effect on cell proliferation. To investigate this in vivo, we did immunohistochemical analysis for Ki67, a marker for proliferation. In the lungs of mice, altered integrinexpressing tumors had significantly less Ki67 staining than they did in GFP-expressing controls (Figure 4Aiv, Biv, Civ, Div and quantitative data shown in Additional File 3), supporting a role for integrin $\alpha 5$ and $\alpha 6$ subunits in regulating tumor growth, in part through effects on cell proliferation.

As described, overexpression of integrin $\alpha 5$ and knockdown of integrin $\alpha 6$ subunits inhibited 4T1 cell proliferation ability. Since cell growth is regulated by positive and negative regulators of the cell cycle, we analyzed the effects of alpha5 integrin and alpha6 integrin subunits on cell-cycle progression and its associated proteins. To understand the mechanism whereby integrin $\alpha 5$ and integrin $\alpha 6$ subunits affect cell proliferation, we examined the cell cycle using $4 \mathrm{~T} 1$ control, 4T1-GFP, 4T1- $\alpha 5$ and 4T1- $\alpha 6$-shRNA1 cells. To determine the effects on cell-cycle progression, we did flow cytometry using propidium iodide. The alpha5 overexpression and knockdown of alpha6 integrin demonstrated a G1/S arrest, which resulted in a decrease in the S-phase population (Figure 5A). This suggested that overexpression of $\alpha 5$ integrin and knockdown of $\alpha 6$ integrin do not allow cells to pass the $S$ phase. As a result, these cells might have inhibited growth.

\section{Gene expression level of cell-cycle-related genes}

To examine the mechanism by which $\alpha 5$ and $\alpha 6$ integrin subunits regulate cell-cycle progression, we did microarray analysis using a cell-cycle gene array containing cell-cycle genes (SA Biosciences). Cell-cycle microarray profiling was done using RNA prepared from 4T1-GFP, 4T1- $\alpha 5$, and 4T1- $\alpha 6$. shRNA1 cells to examine changes in cell-cycle-related genes. We found 


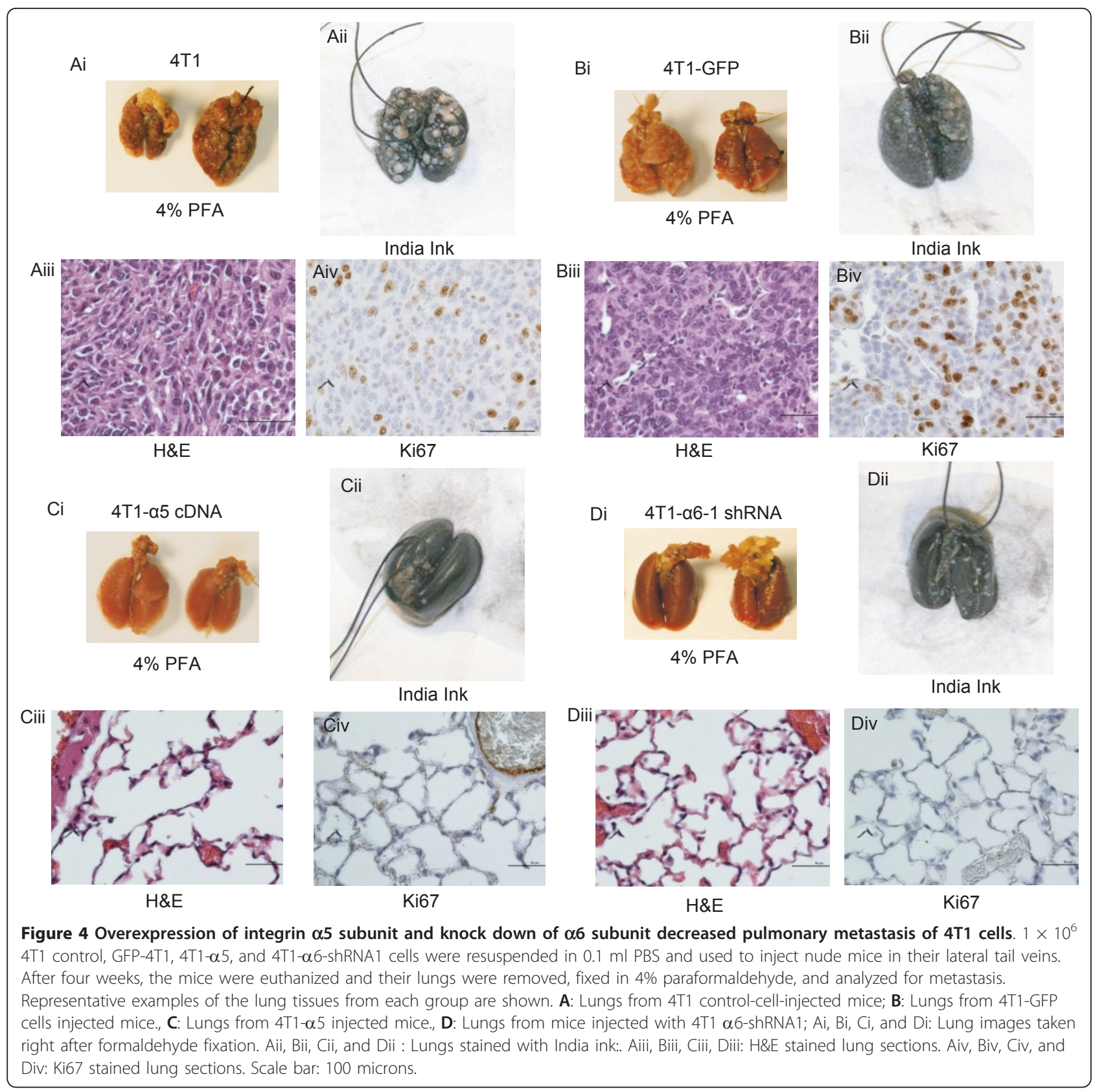

that the expression of chk-1 and E2F-1 was elevated and cyclin E, CDK2 and cdc25A were decreased in 4T1- $\alpha 5$ and 4T1- $\alpha 6$-shRNA1 cells compared to 4T1-GFP cells (Additional File 4). Later, we validated these data by RT-PCR (Figure 5B and data not shown). Although DST gene levels are significantly high in 4T1- $\alpha 5$ and 4T1- $\alpha 6-$ shRNA1 cells, we were unable to validate the data by RT-PCR, and thus it is not further studied. The results suggested that overexpression of alpha5 and knockdown of alpha6 reduces cell growth by enhancing the expression of chk1 and E2F1 and down regulating the expression of cyclin E and CDK2.

\section{Downregulation of cyclin E/CDK2 complexes}

We analyzed the effects of integrin $\alpha 5$ subunit overexpression and $\alpha 6$ subunit knockdown on cell-cycle associated proteins, as shown in Figure 6A, that cells overexpressing $\alpha 5$ integrin and $\alpha 6$ knock-down cells decreased the expression of cyclin E, but not cyclin-D. Consistent with this finding, levels of CDK2, a binding partner of cyclin E, also decreased in the cells. However, no change in the level of CDK4 was observed. These data corroborated the cell cycle array data and suggest that the integrins regulate cell growth through their effects on cell-cycle regulatory proteins. Because it is known that cdc25a regulates CDK2/ 


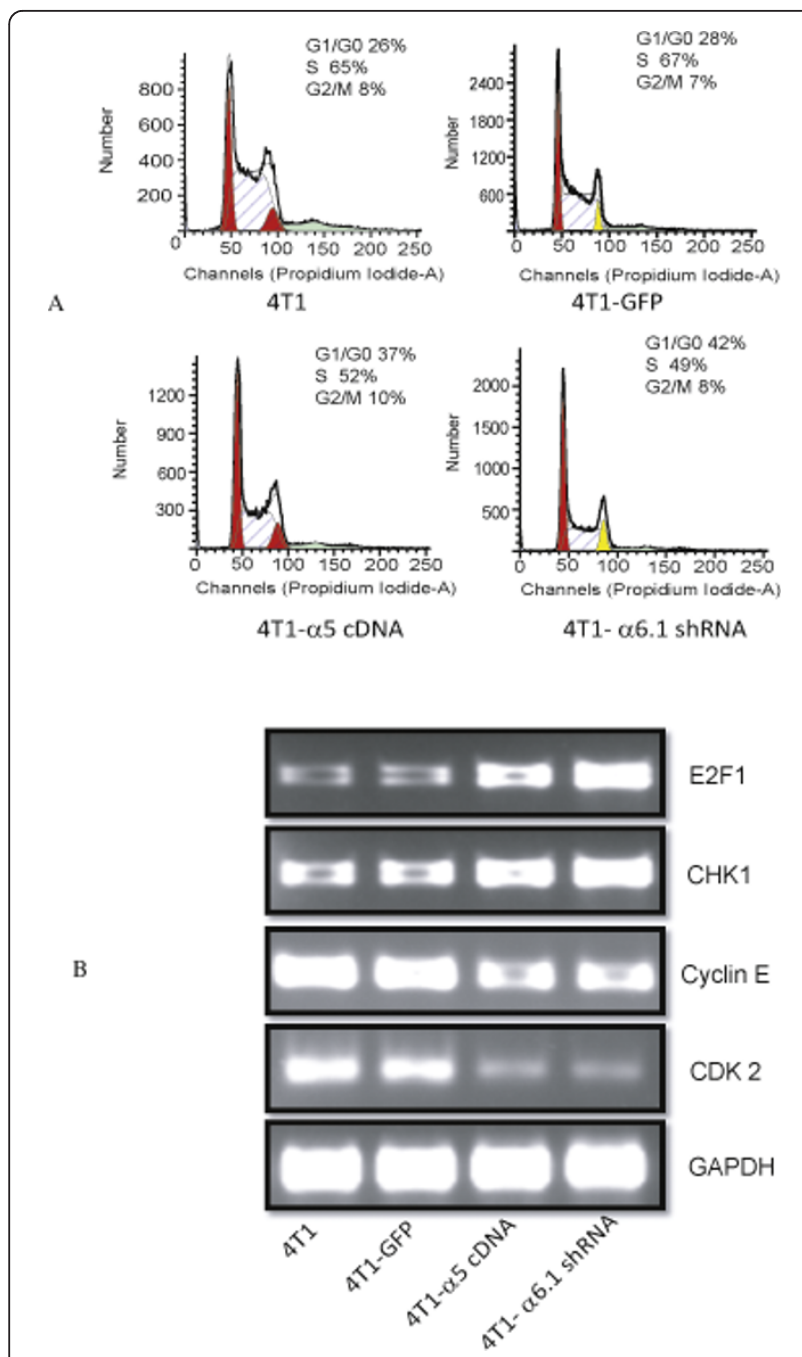

Figure 5 Modulation of integrins regulates cell cycle progression. A: 4T1, GFP-4T1, 4T1- $\alpha 5$, and 4T1- $\alpha 6-$-shRNA1 cells were synchronized and stained with propidium iodide for cell-cycle analysis. Cells were arrested at G1/S stage for 4T1- $\alpha 5$ and $4 \mathrm{~T} 1-\alpha 6-$ shRNA1 (37 and 42) compared to controls (26 and 28), and have shorter $\mathrm{S}$ phase for $4 \mathrm{~T} 1 \alpha 5$ and $4 \mathrm{~T} 1 \alpha 6 \operatorname{shRNA}(52,49)$ compared to controls $(65,67)$. No significant changes in $G 2$ phase were noted (4T1 $\alpha 5: 10,4 T 1 \alpha 6-$ shRNA1;8, 4T1 control: 8, and 4T1 GFP: 7). B. RTPCR data. RNA was isolated from all the four cell lines and RT-PCR was performed for E2F1, chk1, Cyclin E and CDK2. GAPDH control was used as a control.

cyclin E, we examined whether modulation of integrin $\alpha 5$ and $\alpha 6$ subunits have any effect on cdc25a. We found that both overexpression of $\alpha 5$ and knockdown of $\alpha 6$ downregulated the expression of cdc25a (Figure 6A), suggesting that inhibition of cdc25a may be a reason for downregulation of cdk2 and cyclin E.

\section{Upregulation of Chk1 and P27 expression}

We also examined the expression levels of cyclin-dependent kinase inhibitors in the $\mathrm{G} 1 / \mathrm{S}$ phase, finding that the expression level of p27 was significantly increased (Figure 6A). Since our cell-cycle array data indicated that $\alpha 5$ overexpression and $\alpha 6$ integrin subunit-reduced expression caused upregulation of chk1 at the RNA level, we examined the expression of chk 1 at the protein level. Consistent with the RNA data, protein expression levels were also increased, suggesting that chk1 upregulation could be another mechanism by which these integrins regulate metastasis. $\mathrm{Rb}$ phosphorylation is pivotal in controlling cell proliferation by upregulating the G1/S transition of the cell cycle. During the continuous proliferation of cells, $\mathrm{pRb}$ is phosphorylated by the activity of $\mathrm{G} 1$ phase CDKs such as CDK4 and CDK2, thereby liberating factors that control the $\mathrm{S}$-phase entrance. Consistent with our cyclin E/CDK2 data, these integrin modulations inhibited $\mathrm{Rb}$ phosphorylation. Also, to our surprise, we found increased E2F1 levels in these integrin-modulated cells (Figure 6A), which is consistent with the cell-cycle array data. These data suggest $\alpha 5$ and $\alpha 6$ integrin subunits regulate metastasis through their effects on cell cycle regulated proteins.

\section{Discussion}

In this investigation of the expression levels of 8 integrins on the surfaces of cells from mouse breast cancer cell lines 4T1, 4T07, and 67NR, only $\alpha 5$ and $\alpha 6$ integrin subunits showed changes in expression levels in different invasive cell types. The $\alpha 5$ integrin subunit had the lowest expression in highly metastatic 4T1 cells, and little more in 4T07; its highest expression was in 67NR. In contrast, integrin $\alpha 6$ had the opposite expression pattern, as compared to $\alpha 5$ subunit. Our results also showed that overexpression of integrin $\alpha 5$ subunit significantly inhibited $4 \mathrm{~T} 1$ cell proliferation, cell migration, and cell invasion in vitro. Our cell-cycle data indicate that 4T1- $\alpha 5$ cells were arrested at G1/S phase and that a lesser number of cells entered into $S$ phase. Also, our in vivo study showed that pulmonary metastasis of 4T1$\alpha 5$ cells was greatly decreased compared to metastasis of 4T1 and 4T1-GFP cells. Based on these findings, we postulate that integrin $\alpha 5$ subunit functions as an inhibitor of metastasis in mouse breast cancer cell line 4T1. Consistent with our data, lower expression levels of integrin $\alpha 5$ were observed in several cancerous tissues, including hepatocellular carcinoma $[7,13]$, prostate carcinoma [14], and gastric, colorectal, and breast carcinoma [7]. Also previous reports indicated that overexpression of $\alpha 5 \beta 1$ inhibits proliferation of human HT29 colon carcinoma cells in vitro and reduces the formation of lung colonies and cutaneous metastases in vivo $[15,16]$. Similarly, overexpression of integrin $\alpha 5$ in human hepatocellular carcinoma cells reduces cell proliferation, decreases cell colony formation, and changes the cell-cycle pattern [17]. Elevated levels of $\alpha 5 \beta 1$ 
A

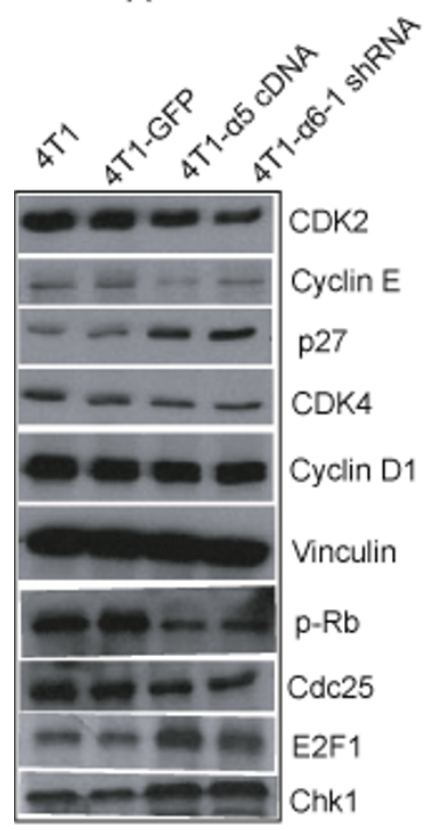

B

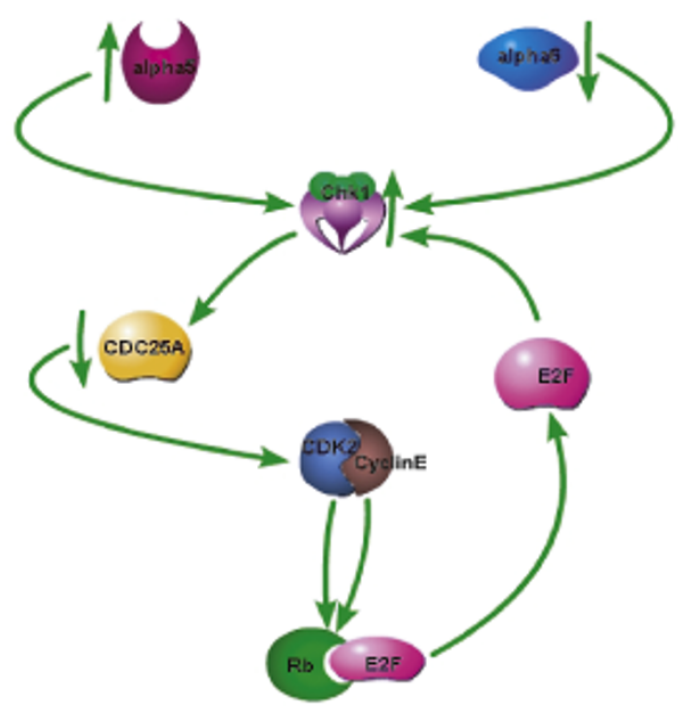

Figure 6 Modulation of integrin expression regulates expression of cell-cycle modulators known to induce G1 arrest. A. Western blots show the expression of cyclin E, cdk2, p27, pRb, chk1, cdc25A, and E2F1 in 4T1 control, 4T1 GFP, 4T1 $\alpha 5$ overexpressing, and 4T1 $\alpha 6$ knockeddown cells. B: Our current model showing the mechanism of integrin modulation in breast cancer progression. This model shows overexpression of integrin $\alpha 5$ or reduced expression of $\alpha 6$ causes upregulation of chk1. This, in turn, causes downregulation of cdk2/cyclin E to reduce phosphorylation of retinoblastoma protein. This integrin modulation enhances the expression of E2F, which may stimulate chk1 expression, which regulates cdc25a function, in a feedback loop mechanism.

suppress the transformed phenotype of Chinese hamster ovary cells [18] and reduce tumorigenesis in a mouse model [19]. Niu et al. found that the proliferation of K562 cells could be inhibited by IFN $\alpha-2 b$ by restoring the function of integrin $\alpha 5$ and $\beta 1$ and enhancing their ability to bind to FN, which in turn upregulates FAK gene expression [20].

There are, however, some contradicting reports showing that integrin $\alpha 5$ may function as an oncogene and is associated with malignant tumor progression. Survival analysis of non small-cell lung cancer patients with integrin $\alpha 5$-overexpressing tumors had a worse overall survival rate than did patients whose tumors had normal integrin $\alpha 5$ expression [21]. Further, the integrin $\alpha 5$ molecule has been reported to promote melanoma metastasis in vitro and in vivo [22]. Integrin $\alpha 5$ up-regulation was identified as the molecular mechanism by which E-cadherin loss promotes tumor progression [23] and ERBB2-mediated transcriptional up-regulation of the $\alpha 5 \beta 1$ promotes tumor cell survival under adverse conditions [24]. Thus, integrin $\alpha 5$ has different functions in different carcinoma cell lines. The reasons for these diverse functions of integrin $\alpha 5$ in cancer progression and metastasis are still unclear; however, it has been suggested that $\alpha 5 \beta 1$ may affect different signaling cascades and might function differently depending on its adhesion or lack of adhesion to fibronectin [21].

Our results show that knockdown of integrin $\alpha 6$ subunit expression inhibited 4T1 cell proliferation, migration, and invasion. Consistent with these findings, the enhancement of cell migration and invasion by integrin $\alpha 6$ ( $\alpha 6 \beta 1$ and $\alpha 6 \beta 4$ ) has been shown in pancreatic carcinoma cells [11], and breast cancer [25]. Unlike integrin $\alpha 5$, which functions as either an oncogene or a tumor suppressor, $\alpha 6$ integrin ( $\alpha 6 \beta 1$ and $\alpha 6 \beta 4$ ) has been implicated only in promoting tumor progression [26-29]. Recent evidence has demonstrated that integrin $\alpha 6$ is necessary for tumorigenicity of a stem-cell-like subpopulation within the MCF7 breast cancer cell line [30]. Integrin $\alpha 6$ can form heterodimers with either $\beta 1$ or $\beta 4$. Both heterodimers ( $\alpha 6 \beta 1$ and $\alpha 6 \beta 4$ ) are receptors for laminin, a component of basement membrane [31]. Higher expression level of $\alpha 6$ ( $\alpha 6 \beta 1$ and $\alpha 6 \beta 4$ ) was also observed in malignant gastrointestinal stromal tumors [32] and human hepatocellular carcinoma cells [17]. These results suggest that alpha 6 integrin is important in tumorigenesis.

Our results indicate that overexpression of $\alpha 5$ integrin and reduction of $\alpha 6$ integrin subunits prevents cells from passing G1/S phase transition, so that cells in $S$ 
phase accumulate. Since our work indicated growth arrest in the G1 phase of the cell cycle and based on PCR array data, we investigated whether cyclin $E$ is affected by integrin modulation. Cyclin E/CDK2 complex is a major regulator of $\mathrm{G} 1 / \mathrm{S}$ phase transition. The major function of cyclin $\mathrm{E}$ is to promote progression through the G1/S phase of the cell cycle by associating with CDK2 to phosphorylate and inactivate retinoblastoma protein and release E2F transcription factors [33]. The activities of the CDKs are regulated by several mechanisms, including binding of cyclins, phosphorylation, and dephosphorylation, as well as binding to CDK inhibitors (CKIs). Overexpression of $\alpha 5$ integrin and downregulation of $\alpha 6$ regulate the expression of cyclin $\mathrm{E}$ and CDK2, but not that of cyclin D. P27Kip1, a member of the cip/Kip family of CKIs, alters the activities of cyclin D1 in quiescent cells, leading to failure of the G1/ $S$ transition and cell-cycle arrest. Our results indicate that the modulation of the integrins enhances p27 expression. Consistent with this, phosphorylation of $\mathrm{pRb}$ is decreased, suggesting that the integrin modulation regulates metastasis affecting $\mathrm{Rb}$ phosphorylation. Furthermore, the changes in integrin expression cause upregulation of chk1 and downregulation of Cdc25A expression. Chk1 inhibits Cdc25A expression, whereas Cdc25A phosphatase dephosphorylates and activates CDK2/cyclin E complex during the G1-S transition in proliferating cells[34]. Cdc25A is negatively regulated by phosphorylation of chk 1 , which is involved in an Sphase check point pathway that responds to genotoxic stress evoked by DNA damaging agents or irradiation [33]. It is currently unknown how chk 1 is induced upon overexpression of $\alpha 5$ or reduction of $\alpha 6$ integrin. In addition, although the mechanism responsible for these changes is not known, our results indicate that E2F1 expression is upregulated as a result of integrin expression changes. Chk1 has been shown to phosphorylate Cdc25A, downregulating its phosphatase activity through distinct mechanisms [34]. For instance, Worms and colleagues reported that chk1 kinase negatively regulates mitotic function of $\mathrm{Cdc} 25 \mathrm{~A}$ phosphatase through 14-3-3 binding[35].

Based on our results, we propose the following model. Integrin $\alpha 5$ subunit overexpression or reduction of $\alpha 6$ subunit integrin upregulates chk 1 , which leads to downregulation of cdc25A; this in turn reduces the activity of cyclin E/CDK2. The reduction of activation causes decreased $\mathrm{pRb}$ phosphorylation and, as a consequence, cell-cycle growth is inhibited. Simultaneously, p27 is upregulated, which also can downregulate the expression CDK2. Furthermore, E2F is upregulated, which may cause enhanced expression of chk1, a regulator of E2F1. This may upregulate chk1 to downregulate cdc25A in a feedback loop mechanism.

\section{Additional material}

Additional file 1: Expression level of integrins of 4T1, 4T07 and 67NR cells by flow cytometry. Percentage expression values of integrins are shown.

Additional file 2: Effect of blocking antibodies on cell migration. A transwell migration was done for 67NR cells with IgG control or with alpha5 integrin blocking antibody on fibronectin and 4T1 cells with IgG control or with alpha6 integrin blocking antibody on laminin. Blocking alpha5 integrin enhanced cell migration while blocking alpha6 antibody decreased cell migration and both the effects are statistically significant.

Additional file 3: Quantitation of Ki67 cells in lung sections. Lung sections stained with Ki67 antibody (described in Aiv, Biv, Civ, and div) were quantitated. The differences between 4T1GFP and 4T1 $\alpha 5$, and 4T1GFP and 4T1 $\alpha 6$ shRNA1 were statistically significant.

Additional file 4: Cell cycle microarray data. RNA prepared from 4T1 control cells, 4T1 GFP, 4T1 $\alpha 5,4 \mathrm{~T} 1 \alpha 6-1$ were used to screen the expression profile of various cell cycle related genes using cell cycle specific arrays quantitative RT PCR assay. Based on average delta CT values, fold change (regulation) was generated and the values were shown in the table. The candidate genes of interest were depicted in bold.

\section{Acknowledgements}

This work was supported by grants from NIH (5RO1CA115706) and funds from the Louisiana Cancer Research Consortium to SKA. SD acknowledges funding from NIH CA127481 and CA129776.

\section{Author details}

${ }^{1}$ Department of Biochemistry and Molecular Biology, Stanley Scott Cancer Center, LSU Health Sciences Center, New Orleans, LA 70112, USA. ${ }^{2}$ Department of Pathology and Laboratory Medicine, Tulane University Medical School, New Orleans, LA 70112, USA.

\section{Authors' contributions}

YW did FACS, cell migration, cell invasion and Western blotting experiments. SS did all animal work and CDNA array experiments. SB did CDNA array experiments, RT PCR and statistical analysis. RR did all cell cycle related Western blots. PJ did specific migration experiments on Firbonectin and Laminin. LB, SH, SD made all the constructs. YW and SKA wrote the manuscript. All authors read and approved the final manuscript.

\section{Competing interests}

The authors declare that they have no competing interests.

Received: 23 February 2011 Accepted: 13 July 2011

Published: 13 July 2011

\section{References}

1. Nguyen DX, Massague J: Genetic determinants of cancer metastasis. Nat Rev Genet 2007, 8:341-352.

2. Yang J: Exploring the molecular basis of tumor metastasis by microarray analysis. Assay Drug Dev Technol 2006, 4:483-488.

3. Avraamides CJ, Garmy-Susini B, Varner JA: Integrins in angiogenesis and lymphangiogenesis. Nat Rev Cancer 2008, 8:604-617.

4. Giancotti FG, Tarone G: Positional control of cell fate through joint integrin/receptor protein kinase signaling. Annu Rev Cell Dev Biol 2003, 19:173-206.

5. Mizejewski GJ: Role of integrins in cancer: survey of expression patterns. Proc Soc Exp Biol Med 1999, 222:124-138.

6. Hwang $\mathrm{R}$, Varner J: The role of integrins in tumor angiogenesis. Hematol Oncol Clin North Am 2004, 18:991-1006, vii.

7. Su JM, Gui L, Zhou YP, Zha XL: Expression of focal adhesion kinase and alpha5 and beta1 integrins in carcinomas and its clinical significance. World J Gastroenterol 2002, 8:613-618.

8. Alahari SK, Reddig PJ, Juliano RL: The integrin-binding protein Nischarin regulates cell migration by inhibiting PAK. Embo J 2004, 23:2777-2788. 
9. Aslakson CJ, Miller FR: Selective events in the metastatic process defined by analysis of the sequential dissemination of subpopulations of a mouse mammary tumor. Cancer Res 1992, 52:1399-1405.

10. Lelekakis M, Moseley JM, Martin TJ, Hards D, Williams E, Ho P, Lowen D, Javni J, Miller FR, Slavin J, Anderson RL: A novel orthotopic model of breast cancer metastasis to bone. Clin Exp Metastasis 1999, 17:163-170.

11. Cruz-Monserrate Z, O'Connor KL: Integrin alpha 6 beta 4 promotes migration, invasion through Tiam 1 upregulation, and subsequent Rac activation. Neoplasia 2008, 10:408-417.

12. Wang $Y$, Rathinam R, Walch A, Alahari SK: ST14 (suppression of tumorigenicity 14 ) gene is a target for miR-27b, and the inhibitory effect of ST14 on cell growth is independent of miR-27b regulation. J Biol Chem 2009, 284:23094-23106.

13. Yao $M$, Zhou $X$, Zha $X$ : [Expression of the integrin alpha 5 subunit in hepatocellular carcinoma]. Zhonghua Yi Xue Za Zhi 1997, 77:382-384.

14. Chen HJ, Wang H, Zhang L, Zhang YK, Wang GM: [Correlation between integrin subunits alpha5 and beta1 expressions in prostate cancer and its clinical implication]. Zhonghua Nan Ke Xue 2006, 12:148-150.

15. Varner JA, Emerson DA, Juliano RL: Integrin alpha 5 beta 1 expression negatively regulates cell growth: reversal by attachment to fibronectin. Mol Biol Cell 1995, 6:725-740

16. Schirner M, Herzberg F, Schmidt R, Streit M, Schoning M, Hummel M, Kaufmann C, Thiel E, Kreuser ED: Integrin alpha5beta1: a potent inhibitor of experimental lung metastasis. Clin Exp Metastasis 1998, 16:427-435.

17. Zhou GF, Ye F, Cao LH, Zha XL: Over expression of integrin alpha 5 beta 1 in human hepatocellular carcinoma cell line suppresses cell proliferation in vitro and tumorigenicity in nude mice. Mol Cell Biochem 2000, 207:49-55.

18. Giancotti FG, Ruoslahti E: Elevated levels of the alpha 5 beta 1 fibronectin receptor suppress the transformed phenotype of Chinese hamster ovary cells. Cell 1990, 60:849-859.

19. Plantefaber LC, Hynes RO: Changes in integrin receptors on oncogenically transformed cells. Cell 1989, 56:281-290.

20. Niu ZY, Pan L, Zhang XJ, Liu YJ: [Regulatory effect of integrin alpha5 and beta1 on proliferation inhibition of $\mathrm{K} 562$ cells induced by interferon alpha-2b]. Ai Zheng 2006, 25:297-302.

21. Adachi M, Taki T, Higashiyama M, Kohno N, Inufusa H, Miyake M: Significance of integrin alpha5 gene expression as a prognostic factor in node-negative non-small cell lung cancer. Clin Cancer Res 2000, 6:96-101.

22. Qian F, Zhang ZC, Wu XF, Li YP, Xu Q: Interaction between integrin alpha (5) and fibronectin is required for metastasis of B16F10 melanoma cells. Biochem Biophys Res Commun 2005, 333:1269-1275.

23. Sawada K, Mitra AK, Radjabi AR, Bhaskar V, Kistner EO, Tretiakova M, Jagadeeswaran S, Montag A, Becker A, Kenny HA, Peter ME, Ramakrishnan V, Yamada SD, Lengyel E: Loss of E-cadherin promotes ovarian cancer metastasis via alpha 5-integrin, which is a therapeutic target. Cancer Res 2008, 68:2329-2339.

24. Spangenberg C, Lausch EU, Trost TM, Prawitt D, May A, Keppler R, Fees SA, Reutzel D, Bell C, Schmitt S, Schiffer IB, Weber A, Brenner W, Hemes M, Sahin U, Tureci O, Koelbl H, Hengstler JG, Zabel BU: ERBB2-mediated transcriptional up-regulation of the alpha5beta1 integrin fibronectin receptor promotes tumor cell survival under adverse conditions. Cancer Res 2006, 66:3715-3725.

25. Yang $\mathrm{XH}$, Richardson AL, Torres-Arzayus Ml, Zhou P, Sharma C, Kazarov AR, Andzelm MM, Strominger JL, Brown M, Hemler ME: CD151 accelerates breast cancer by regulating alpha 6 integrin function, signaling, and molecular organization. Cancer Res 2008, 68:3204-3213.

26. Mercurio AM, Bachelder RE, Chung J, O'Connor KL, Rabinovitz I, Shaw LM Tani T: Integrin laminin receptors and breast carcinoma progression. J Mammary Gland Biol Neoplasia 2001, 6:299-309.

27. Mercurio AM, Rabinovitz I: Towards a mechanistic understanding of tumor invasion-lessons from the alpha6beta 4 integrin. Semin Cancer Biol 2001, 11:129-141.

28. Mercurio AM, Rabinovitz I, Shaw LM: The alpha 6 beta 4 integrin and epithelial cell migration. Curr Opin Cell Biol 2001, 13:541-545.

29. Chung J, Kim TH: Integrin-dependent translational control: Implication in cancer progression. Microsc Res Tech 2008, 71:380-386.

30. Cariati M, Naderi A, Brown JP, Smalley MJ, Pinder SE, Caldas C, Purushotham AD: Alpha- 6 integrin is necessary for the tumourigenicity of a stem cell-like subpopulation within the MCF7 breast cancer cell line. Int J Cancer 2008, 122:298-304.
31. Chung J, Mercurio AM: Contributions of the alpha6 integrins to breast carcinoma survival and progression. Mol Cells 2004, 17:203-209.

32. Takeyama H, Funahashi H, Sawai H, Takahashi H, Yamamotorm M, Akamo Y, Manabe T: Expression of alpha6 integrin subunit is associated with malignancy in gastric gastrointestinal stromal tumors. Med Sci Monit 2007, 13:CR51-56.

33. Inoue $Y$, Kitagawa M, Taya Y: Phosphorylation of pRB at Ser612 by Chk1/2 leads to a complex between PRB and E2F-1 after DNA damage. EMBO J 2007, 26:2083-2093.

34. Kreutzer J, Guerra B: The regulatory beta-subunit of protein kinase CK2 accelerates the degradation of $\mathrm{CDC} 25 \mathrm{~A}$ phosphatase through the checkpoint kinase Chk1. Int J Oncol 2007, 31:1251-1259.

35. Chen MS, Ryan CE, Piwnica-Worms H: Chk1 kinase negatively regulates mitotic function of Cdc25A phosphatase through 14-3-3 binding. Mol Cell Biol 2003, 23:7488-7497.

doi:10.1186/1476-4598-10-84

Cite this article as: Wang et al.: Integrin subunits alpha5 and alpha6 regulate cell cycle by modulating the chk1 and Rb/E2F pathways to affect breast cancer metastasis. Molecular Cancer 2011 10:84.

\section{Submit your next manuscript to BioMed Central and take full advantage of:}

- Convenient online submission

- Thorough peer review

- No space constraints or color figure charges

- Immediate publication on acceptance

- Inclusion in PubMed, CAS, Scopus and Google Scholar

- Research which is freely available for redistribution

Submit your manuscript at www.biomedcentral.com/submit
C) Biomed Central 